\title{
Modeling the Effect of Energy Status on Mammary Gland Growth and Lactation
}

\author{
I. Vetharaniam,* S. R. Davis, ${ }^{*}$ M. Upsdell, ${ }^{*}$ E. S. Kolver,† and A. B. Pleasants* \\ *AgResearch Limited, Private Bag 3123, Hamilton, New Zealand \\ †Dexcel Limited, Private Bag 3221, Hamilton, New Zealand
}

\begin{abstract}
The impact of nutrition on lactation can be separated into acute effects, affecting day-to-day yield, and chronic effects, which govern the persistency of lactation and rate of decline of the lactation curve. A mathematical model of the mammary gland was constructed to investigate both acute and chronic effects. Mammary growth is expressed in terms of the dynamics of populations of active (secreting) and quiescent (engorged) alveoli. The secretion rate of active alveoli is expressed in terms of the energy status of the dam.

The model was fitted to data from a $2 \times 2$ factorial trial in which lactation curves were measured for heifers of two different genotypes (North American and New Zealand Holstein-Friesians) fed two different diets [grass and total mixed rations (TMR)]. Total formation of alveoli during pregnancy and lactation was statistically the same across all groups despite differences between diets, in the rate of formation of alveoli at parturition.

The senescence rate of alveoli was significantly higher for heifers fed grass compared with heifers fed TMR, which corresponds to better persistency for heifers fed TMR. Heifers fed TMR had a higher rate of reactivation of quiescent alveoli than heifers fed grass, which also contributes to increased persistence for heifers fed TMR. There was a genotype $\times$ diet interaction in the rate of quiescence of active alveoli: the North American-Grass group had a higher rate of quiescence than the other three groups, perhaps reflecting differences in selection pressures between the New Zealand and North American genotypes.
\end{abstract}

(Key words: mammary gland, modeling, nutrition, milk production)

Abbreviation key: $\mathbf{M E}=$ metabolizable energy, $\mathbf{P Q}=$ pasture quality.

Received September 23, 2002.

Accepted February 10, 2003.

Corresponding author: I. Vetharaniam; e-mail: kumar. vetharaniam@agresearch.co.nz.

\section{INTRODUCTION}

A mathematical model of lactation that can predict production under a variety of situations is useful from both management and breeding points of view. A large number of lactation models already exist, and these can be divided into empirical and mechanistic models. Empirical models can be regarded as primarily data based, whereas mechanistic models consider underlying structure and interaction (with some degree of abstraction). The detail and level of representation in mechanistic models varies widely, and from a philosophical viewpoint there are no purely empirical or purely mechanistic models (Nestorov et al., 1999). Thus, Nestorov et al. (1999) note the distinction between empirical and mechanistic "can only be relative, reflecting the predominance of empirical or mechanistic elements in a particular model." In this paper "mechanistic" is used to describe any model that addresses the underlying biological processes, at some level, in order to predict outcomes. Perhaps the most widely used model of a whole lactation is the empirical model given by Wood (1967), which, although originally developed for cattle, has been fitted to lactation curves in sheep (Sakul and Boylan, 1992) and goats (Williams, 1993). Numerous alternative empirical models have been proposed (for example, Jenkins and Ferrell, 1984; Emmans and Fisher, 1986; Morant and Gnanasakthy, 1989). Papajcsik and Bodero (1988) reviewed a number of lactation models; Hohenboken et al. (1992), Williams (1993), and Olori et al. (1999) gave a comparison of the performance of some models in fitting lactation curves. Whereas empirical models can provide good fits to data, they tend to suffer from a lack of portability and do not lend themselves to useful biological interpretation, as has been noted by Wood (1977). In comparison with the number of empirical models, the number of mechanistic models is small (Friggens et al., 1999). The first attempt at a mechanistic model of lactation can be traced to Neal and Thornley (1983), in whose model division of undifferentiated cells produces secretory cells of finite life, with secretory activity and cell death influenced by the presence of milk in the udder. However, the parameter requirements of this model are considered 
(Williams, 1993; Dijkstra et al., 1997) to preclude the model from practical use. Dijkstra et al. (1997) constructed a mechanistic model of mammary gland growth and lactation to produce a single, explicit equation for milk production. Dijkstra et al. (1997), like Neal and Thornley (1983), assumed a single pool of secretory cells in the udder, with one influx and one efflux. Endocrine changes associated with pregnancy were assumed to cause the proliferation of secretory cells through the division of undifferentiated cells, continuing into early lactation. Efflux from the pool was caused by cell death during lactation. The patterns of cellular differentiation during mammary gland development, and the decline of cells leading to involution have been documented by Knight and Wilde (1993).

The model constructed by Dijkstra et al. (1997) has more biological basis than that of Neal and Thornley (1983). However, it can be improved in three ways. First, whereas Neal and Thornley (1983) and Dijkstra et al. (1997) considered that the mammary gland consisted of only one pool of secretory cells, Molenaar et al. (1992) found that milk protein gene expression varied widely throughout the mammary gland in sheep and cattle. The existence of two types of alveoli was shown, some actively secreting and others that were quiescent. Second, the influence of nutrition or energy intake on mammary gland growth and performance were not considered by Dijkstra et al. (1997), nor by Neal and Thornley (1983)—milk yield responds rapidly to nutritional stress (Knight et al., 1994), although energydeficient cows will partially buffer milk production at the expense of body reserves (Somerville et al., 1983). Third, the effect of milking frequency was ignored. This paper addresses the first two of these concerns by development of a mammary gland model as two interacting pools of alveoli (active and quiescent), with milk production being related to both the number of alveoli and the energetic status of the dam. The predictions of this model are then compared with experimental data to indicate how energy status affects the dynamics of mammary gland growth. Modeling the third concern, the effect of milking frequency on mammary growth, results in additional mathematical complexity (Shorten et al., 2002). The data used in this paper was from heifers milked twice daily only, and thus the effects of different milking frequencies could be ignored, allowing the use of a simpler model more amenable to comparison with data.

\section{MODEL DEVELOPMENT}

\section{Composition of the Mammary Gland}

The mammary gland consists of active and quiescent alveoli, each alveolus being made up of approximately
150 to 300 secretory cells (Weber et al., 1955). Active alveoli secrete milk, whereas the quiescent alveoli have lost this ability and also show no expression of casein genes (Molenaar et al., 1992) but have high levels of lactoferrin expression. This observation of heterogeneity of gene expression was confirmed in biopsy tissue from the udders of lactating cows (Farr et al., 1996), where quiescent alveoli were in the order of $10 \%$ of the total alveolar population. Individual cells within an alveolus, and indeed within lobules of alveoli, all conformed to the same type of gene expression. Thus, quiescent and active lobules could be distinguished on the basis of lactoferrin or casein expression (Molenaar et al., 1992). For the purpose of this model the alveolus is considered to be the 'base functional unit' for secretion, and it is hypothesized that when cells are lost from the mammary gland they are lost as whole alveoli, either disappearing entirely or partly, with some cells remaining in the gland in an undifferentiated state.

\section{Effect of Energy Status on Milk Production}

In this paper, milk production is expressed in terms of energy content of the milk (i.e., MJ/d) rather than the usual liters per day or kilograms per day. The number of active alveoli is denoted by $A$, and the number of quiescent alveoli by $Q$. Let $S$ be the maximum milk energy secretion rate of the average, active alveolus, in $\mathrm{MJ} / \mathrm{d}$. Then, the maximum milk production rate $(P$, on an energetic basis) of the mammary gland is

$$
P=S A
$$

Underlying this expression for $P$ is the assumption that the dam is being milked sufficiently frequently that the udder is never filled to capacity (in which case milk pressure prevents further secretion). This assumption regarding udder fill appears to be valid for the data that were used, where heifers were milked twice daily: typically, Holsteins fed concentrates take approximately $18 \mathrm{~h}$ or more to fill their udder to capacity (Davis et al., 1998, 1999), and the effects of udder fill are likely to have a negative effect only for cows milked once per day. The Vetharaniam et al. (2001) model for animal energetics includes a pool, $N$, which corresponds to the energy flux in the blood of an animal. $N$ has a maximum value, $N_{u}$, which corresponds to a maximal level of nutrition (which may not be realized because of digestive constraints). Partitioning of energy for each mode of energy utilization (e.g., pregnancy, lactation, or growth) is done through this pool in terms of an "energy status," $E$, which we define as the ratio:

$$
E=N / N_{u},
$$




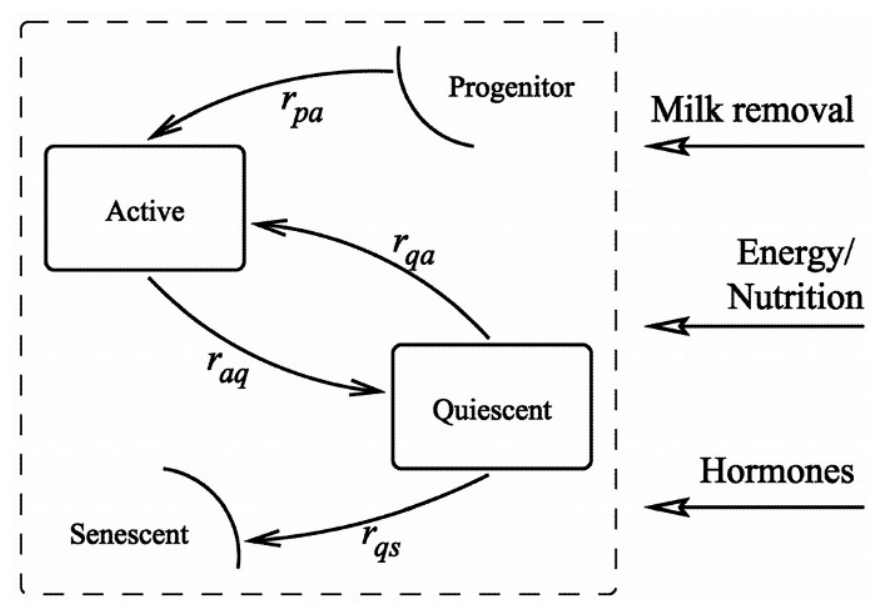

Figure 1. Partitioning of mammary secretory cells in the udder into dynamically interacting components.

taking a value between 0 and 1 . Daily milk production is given as a "current" of milk energy, $I$, expressed in $\mathrm{MJ} \mathrm{d}^{-1}$, where

$$
I=E^{L} P
$$

when $E=1$ (maximal nutrition), $I=P$ (maximal milk production). The power $L$ (unitless) is an "elasticity of production" parameter that governs the response of milk yield to nutrition, when $E<1$ (when nutrition is not maximal). If $L=0$, milk production is unresponsive to energy status, $E$. If $L=1$, milk production decreases linearly with $E$. In principle, $L$ might be affected by pregnancy status. However, for simplicity, $L$ is assumed constant.

\section{Alveolar Dynamics}

The mammary gland is conceptualized as in Figure 1 into a pool of active alveoli, $A$, and a pool of quiescent alveoli, $Q$. The active pool has two inflows-division of progenitor cells (undifferentiated cells) at a rate $r_{p a}$, and the reactivation of quiescent alveoli at a rate $r_{q a}$. Quiescence of active alveoli, at rate $r_{a q}$, is the only sink for the active pool, and provides the sole influx for the quiescent pool. The quiescent pool has two sinks: the reactivation of quiescent alveoli, and the senescence of quiescent alveoli at rate $r_{q s}$. Although quiescent alveoli are not secreting, they have the potential to become active, and thus store latent secretory capability. The senescence of quiescent cells reduces this capability, and the greater the rate of senescence, the less persistent the lactation.

The change with time of $A$ and $Q$ are given in terms of these rates:

$$
\begin{aligned}
& \frac{\mathrm{d} A}{\mathrm{~d} t} \equiv r_{p a}-r_{a q}+r_{q a} \\
& \frac{\mathrm{d} Q}{\mathrm{~d} t} \equiv r_{a q}-r_{q a}+r_{q s}
\end{aligned}
$$

Hormonal, nutritional, physiological, and management factors can all be expected to impact on these rates of flow into and from both pools. In the absence of knowledge regarding the way in which nutrition affects each of these rates, it is hypothesized, as a first approximation, that none of these rates is affected by nutrition (or energy status). This is taken as a null hypothesis, and it is tested in this paper. Expressions for the rates of flow are taken as follows. Let $t$ be the time from parturition. The rate of production of active alveoli by progenitor cells, $r_{p a}$ is given an initial value $k_{1}$ (units $\mathrm{d}^{-1}$ ), and following Neal and Thornley (1983) it is assumed that $r_{p a}$ decays exponentially, with time constant $k_{2}$ :

$$
r_{p a}=k_{1} \exp \left(-k_{2} t\right)
$$

It is assumed that $r_{a q}$, the rate of quiescence of active alveoli, is proportional to active alveolar number, $A$, by a factor $k_{3}$ (units $\mathrm{d}^{-1}$ ). It is further assumed that $r_{q a}$ and $r_{q s}$, the respective rates of reactivation and senescence of quiescent alveoli are proportional to the quiescent alveoli population, $Q$, with respective proportionality constants $k_{4}$ and $k_{5}$, both with units $\mathrm{d}^{-1}$.

$$
\begin{aligned}
& r_{a q}=k_{3} A \\
& r_{q a}=k_{4} Q \\
& r_{q s}=k_{5} Q
\end{aligned}
$$

Substituting equations 6 and 7 to 9 into equations 4 and 5 gives the following set of differential equations for the evolution of active and quiescent alveolar numbers with time.

$$
\begin{gathered}
\frac{\mathrm{d} A}{\mathrm{~d} t}=k_{1} \exp \left(-k_{2} t\right)-k_{3} A+k_{4} Q \\
\frac{\mathrm{d} Q}{\mathrm{~d} t}=k_{3} A-\left(k_{4}+k_{5}\right) Q
\end{gathered}
$$

The presence of quiescent alveoli requires that some active alveoli have lactated and experienced prolonged engorgement resulting in a change in gene expression. Very near the start of a lactation, it is unlikely that any alveoli will have been in an engorged state for 
long enough to induce them to quiesce. Therefore it is assumed that there are no quiescent alveoli at parturition. Thus the initial condition, $A=A_{0}$ and $Q=0$ when $t=0$, is imposed, where $A_{0}$ is a constant. The system of differential equations formed by equations 10 and 11 can be solved explicitly, and has the following solution:

$$
\begin{aligned}
& A=d e^{-k_{2} t}+l_{6} e^{w_{6} t}+l_{7} e^{w_{7} t}, \\
& Q=c e^{-k_{2} t}+q_{6} e^{w_{6} t}+q_{7} e^{w_{7} t},
\end{aligned}
$$

where $d, l_{6}, l_{7}, w_{6}, w_{7}, c, q_{6}$, and $q_{7}$ are functions of the parameters $A_{0}, k_{1}, k_{2}, k_{3}, k_{4}$, and $k_{5}$ :

$$
\begin{gathered}
c \equiv \frac{k_{1} k_{3}}{k_{2}\left(k_{2}-k\right)+k_{3} k_{5}} \\
d \equiv \frac{c}{k_{3}}\left(k_{4}+k_{5}-k_{2}\right) \\
w_{6} \equiv-\frac{k}{2}+\frac{1}{2} \sqrt{k^{2}-4 k_{3} k_{5}} \\
w_{7} \equiv-\frac{k}{2}+\frac{1}{2} \sqrt{k^{2}-4 k_{3} k_{5}} \\
l_{6} \equiv \frac{q_{6}}{k_{3}}\left(w_{6}+k_{4}+k_{5}\right) \\
l_{7} \equiv \frac{q_{7}}{k_{3}}\left(w_{7}+k_{4}+k_{5}\right) \\
k \\
q_{6} \equiv \frac{\left(w_{7}+k_{4}+k_{5}\right) c+A_{0} k_{3}}{w_{6}-w_{7}} \\
q_{7} \equiv-\frac{\left(w_{6}+k_{2}\right) c+A_{0} k_{3}}{w_{6}-w_{7}}
\end{gathered}
$$

Substituting equations 1 and 12 into equation 3 gives the following lactation curve as a function of energetic status and time since parturition.

$$
I=S E^{L}\left(d e^{-k_{2} t}+l_{6} e^{w_{6} t}+l_{7} e^{w_{7} t}\right)
$$

Equations 12 and 13, for the evolution of the active and quiescent alveoli pools, were developed with the implicit assumption that milking frequency and nutritional effects on alveolar dynamics are not changing with time. For a lactating animal subjected to varying levels of energy/nutrient deficit, the assumption of constant nutritional effect is unrealistic since, in cattle at least, alveolar capacity is affected by diet (Davis et al., 2000). The goal of this paper is to estimate the effect of nutrition on the rates expressed by equations 6 to 9 , by a statistical estimation involving the fitting of the model to experimental data.

\section{Model Fitting}

Equation 23 was fitted to time-series data for milk production, $I(\mathrm{MJ} / \mathrm{d})$, using the times series data for the energy status, $E$, of the dam and a theoretical value for the milk secretion rate $S$. This allowed the estimation of the parameter $L$ and the values of the bracketed terms $\left(d e^{-k_{2} t}+l_{6} \mathrm{e}^{w_{6} t}+l_{7} \mathrm{e}^{w_{7} t}\right)$ for each of the data times, which in turn allowed the parameters $A_{0}, k_{1}, k_{2}, k_{3}, k_{4}$, and $k_{5}$ to be estimated (equations 14 to 22). Typically, time series measurements on the populations of active and quiescent alveoli are difficult to obtain. However, knowing the parameters in equations 14 to 22 allows the use of equations 12 and 13 to estimate these populations. Data used for this procedure came from a $2 \times 2$ factorial trial in which 48 primiparous, 2-yr-old heifers of two different genotypes New Zealand HolsteinFriesian vs. North American Holstein-Friesian (The North American genotype included heifers from The Netherlands and the United States, with the origins of the Dutch heifers being in North America within the last $10 \mathrm{yr}$.)] were fed on two different diets [all-pasture (grass) vs. TMR] (Kolver et al., 2000). Data available from the trial were recorded at weekly intervals and included both liveweight and weekly averages of daily milk production for each heifer.

To obtain values for the energy status, $E$, of each heifer, the lactation model should be coupled with its complementary animal model (Vetharaniam et al., 2001), and the resultant larger model being fitted to intake, weight, and lactation data. However, pasture intake data for the trial, which were measured from rising plate meter assesments, were considered unreliable because high pasture allowances resulted in similar pre- and postgrazing pasture masses. Thus another approach was used: an estimated energy status, $E$, was calculated energy status as the ratio of estimated energy intake to estimated maximum energy intake. Energy intake, specified in terms of MJ metabolizable energy (ME) per day, was estimated using equations from Holmes and Wilson (1984), which relate performance to intake. The empirical relationships given by Holmes and Wilson (1984), being based on a number of different studies, provide useful estimates of intake. Using these equations to estimate intakes for heifers fed TMR as well as for those fed grass, ensured consistency between the treatments and avoided biasing parameter estimates. Estimated maximum energy intake for each 
heifer was evaluated as energy required for maximum growth plus energy required for maintenance plus energy required for maximum milk production. The maximum gain observed (after liveweight curves had been smoothed to remove noise) was $1.96 \mathrm{~kg} / \mathrm{d}$. Maximum daily gain in live weight for each heifer was assumed to be $2 \mathrm{~kg} / \mathrm{d}$ and the energy associated with this gain as $38.5 \mathrm{MJ} / \mathrm{kg}$ (Holmes and Wilson, 1984). Maintenance energy requirements for lactating cattle of liveweight $W$, grazing pasture containing more than $11 \mathrm{MJ}$ of ME/ $\mathrm{kg} \mathrm{DM}$ is given by Holmes and Wilson (1984) as $0.6 W^{0.75}$ $\mathrm{MJ} / \mathrm{d}$. The pasture quality (PQ) available to the heifers in the trial varied from 9 to $13.4 \mathrm{MJ}$ of $\mathrm{ME} / \mathrm{kg} \mathrm{DM}$, and thus the maintenance coeffcient value of 0.6 was replaced by $0.51-0.02 \times \mathrm{PQ}$ to account for the changing efficiencies associated with changing PQ (Holmes and Wilson, 1984). Holmes and Wilson (1984) accounted for moderate activity in their maintenance equation, appropriate for the animals in this study, which walked an average of $350 \mathrm{~m}$ to the milking shed. Maximum milk production was approximated by actual milk production (possibly underpredicting by $20 \%$ ). The energy content of milk was obtained assuming that the energy densities of lactose, fat, and protein in milk are, respectively, 25.0, 56.2, and $31.8 \mathrm{MJ} / \mathrm{kg}$, with an additional energy content of $0.6 \mathrm{MJ} / \mathrm{L}$ of milk volume (Dado et al., 1993). For every megajoule of milk energy produced, an additional $0.25 \mathrm{MJ}$ of energy was assumed to be lost as heat (this corresponds to $80 \%$ efficiency in milk production).

The actual energy usage was then estimated on the basis of energy corresponding to an increase or decrease in live weight (32.0 MJ/kg; Holmes and Wilson, 1984) plus the energy for maintenance, plus 1.25 times the energy of milk produced. Eight parameters govern the production of milk energy (refer to equation 23 and the identities given in equations 14 to 22). Of these, $S$, the maximum secretion rate for an "average" alveolus was assigned a theoretical value of $3 \times 10^{-9} \mathrm{MJ} / \mathrm{d}$. This was based on a maximum production of $25 \mathrm{~L} / \mathrm{d}$ for an udder containing $50 \mathrm{~g}$ of DNA (S. R. Davis, unpublished data), producing milk with energy concentration of 3.32 $\mathrm{MJ} \mathrm{L}^{-1}$ (the average over the trial), with each secretory cell having $8 \mathrm{pg}$ of DNA, and assuming that there are 150 to 300 cells per alveolus (Weber et al., 1955).

The remaining seven parameters $\left(A_{0}, k_{1}, k_{2}, k_{3}, k_{4}\right.$, $k_{5}$, and $L$ ) were fitted to the data for each heifer using a nonlinear least squares method. The algorithm used was a modified version of Brent's (1973) enhancement to Powell's conjugate directions minimization method. For each parameter, the set of 48 estimates, one for each heifer, was analyzed by an analysis of variance to ascertain the effects of breed and diet, using the statistical computer package Genstat 5 release 4.2.

\section{RESULTS}

The least square means of the analysis are presented in Table 1 . In the statistical analysis, there were, respectively, 9, 10, 14, and 15 animals in the North American-Grass, North American-TMR, New Zealand-Grass, and New Zealand-TMR treatment groups. No genotype or diet effects were found on $A_{0}$, the population of active alveoli at parturition, which had a mean value of 1.92 $\times 10^{10}$ across all the animals. $k_{1}$, which has a positive, linear effect on the rate at which new alveoli are produced, had a mean value across all groups of $1.44 \times 10^{9}$ $\mathrm{d}^{-1}$. There was a diet effect on $k_{1}$, with $k_{1}$ being lower for TMR than for grass $(P<0.05)$. However, it is unlikely that a higher nutritional level would give rise to a lower proliferation rate for alveoli, and thus the explanation for this result is unclear. There was no genotype or diet effect on $k_{2}$, which governs the rate at which the production of new alveoli declines with time. $k_{2}$ had a mean value across all groups of $1.50 \times 10^{-1} \mathrm{~d}^{-1}$.

The total production of new alveoli by progenitor cells over the course of a lactation is given obtained by integrating $r_{p a}$ (equation 6) from parturition $(t=0)$ until the end of lactation. Typically, $r_{p a}$ falls to zero considerably before the end of a lactation, and thus total production during a lactation is $k_{1} / k_{2}$. Assuming negligible loss of alveoli during pregnancy (Dijkstra et al., 1997), the total production of alveoli during the period from conception until the end of lactation is

$$
A_{\text {produced }}=A_{0}+\frac{k_{1}}{k_{2}} .
$$

Comparing $A_{\text {produced }}$ across groups showed no genotype, diet, or genotype-diet effects. This suggests that the total number of alveoli produced during a lactation is to a large extent fixed, leading one to speculate that soon after conception, a fixed pool of mammary progenitor cells is initialized, and that production of alveoli continues until this pool is exhausted.

$k_{3}$, which governs the rate of quiescence of active alveoli showed no diet or genotype effects, but did show a genotype-diet interaction effect $(P<0.05)$. For North American heifers fed grass, $k_{3}$ had a value of $4.38 \times 10^{-}$ ${ }^{1} \mathrm{~d}^{-1}$, compared with $3.39 \times 10^{-1} \mathrm{~d}^{-1}$ for North American heifers fed grass. There was no difference in $k_{3}$ between diets for New Zealand heifers, which had a value for $k_{3}$ of $3.62 \times 10^{-1} \mathrm{~d}^{-1}$, nor between the North American TMR group and New Zealand heifers. This indicates that alveoli in North American heifers fed grass could be more susceptible to quiescence than in the other groups. The average value for $k_{3}$ across the trial was $3.72 \times 10^{-1} \mathrm{~d}^{-1}$.

$k_{4}$, which governs the rate of reactivation of quiescent alveoli, showed a diet effect $(P<0.05) . k_{4}$ had a 
Table 1. Least square means for the parameters, standard errors of the difference (SED) between the means, and standard errors of the parameters (in parentheses). ${ }^{1}$

\begin{tabular}{|c|c|c|c|c|c|c|}
\hline & & [SED] & Grass & TMR & Mean & [SED] \\
\hline$A_{0}\left(\times 10^{10}\right)$ & $\begin{array}{l}\text { North American } \\
\text { New Zealand } \\
\text { Mean }\end{array}$ & {$[0.14]$} & $\begin{array}{l}1.83(0.16) \\
2.10(0.13) \\
2.00\end{array}$ & $\begin{array}{l}1.95(0.15) \\
1.79(0.12) \\
1.85\end{array}$ & $\begin{array}{l}1.89 \\
1.94 \\
1.92\end{array}$ & {$[0.14]$} \\
\hline$k_{1}\left(\times 10^{9} \mathrm{~d}^{-1}\right)$ & $\begin{array}{l}\text { North American } \\
\text { New Zealand } \\
\text { Mean }\end{array}$ & $*[0.16]$ & $\begin{array}{l}1.45(0.18) \\
1.73(0.15) \\
1.62\end{array}$ & $\begin{array}{l}1.42(0.17) \\
1.18(0.14) \\
1.28\end{array}$ & $\begin{array}{l}1.43 \\
1.45 \\
1.44\end{array}$ & {$[0.17]$} \\
\hline$k_{2}\left(\times 10^{-1} \mathrm{~d}^{-1}\right)$ & $\begin{array}{l}\text { North American } \\
\text { New Zealand } \\
\text { Mean }\end{array}$ & {$[0.30]$} & $\begin{array}{l}1.21(0.34) \\
2.06(0.27) \\
1.73\end{array}$ & $\begin{array}{l}1.50(0.32) \\
1.16(0.26) \\
1.30\end{array}$ & $\begin{array}{l}1.37 \\
1.59 \\
1.50\end{array}$ & {$[0.31]$} \\
\hline$k_{3}\left(\times 10^{-1} \mathrm{~d}^{-1}\right)$ & $\begin{array}{l}\text { North American } \\
\text { New Zealand } \\
\text { Mean }\end{array}$ & {$[0.24]$} & $\begin{array}{l}4.38(0.27)^{*} \\
3.56(0.21) \\
3.88\end{array}$ & $\begin{array}{l}3.39(0.25) \\
3.68(0.21) \\
3.56\end{array}$ & $\begin{array}{l}3.86 \\
3.62 \\
3.72\end{array}$ & {$[0.25]$} \\
\hline$k_{4}\left(\times \mathrm{d}^{-1}\right)$ & $\begin{array}{l}\text { North American } \\
\text { New Zealand } \\
\text { Mean }\end{array}$ & $*[0.46]$ & $\begin{array}{l}4.93(0.53) \\
4.33(0.43) \\
4.56\end{array}$ & $\begin{array}{l}5.54(0.50) \\
5.56(0.41) \\
5.55\end{array}$ & $\begin{array}{l}5.25 \\
4.97 \\
5.08\end{array}$ & {$[0.47]$} \\
\hline$k_{5}\left(\times 10^{-2} \mathrm{~d}^{-1}\right)$ & $\begin{array}{l}\text { North American } \\
\text { New Zealand } \\
\text { Mean }\end{array}$ & $* * *[0.45]$ & $\begin{array}{l}3.76(0.51) \\
2.86(0.41) \\
3.22\end{array}$ & $\begin{array}{l}0.94(0.48) \\
1.60(0.40) \\
1.33\end{array}$ & $\begin{array}{l}2.28 \\
2.20 \\
2.23\end{array}$ & {$[0.46]$} \\
\hline$L\left(\times 10^{-1}\right)$ & $\begin{array}{l}\text { North American } \\
\text { New Zealand } \\
\text { Mean }\end{array}$ & {$[0.45]$} & $\begin{array}{l}5.67(0.53) \\
5.99(0.42) \\
5.86\end{array}$ & $\begin{array}{l}5.07(0.50) \\
5.78(0.41) \\
5.50\end{array}$ & $\begin{array}{l}5.36 \\
5.88 \\
5.67\end{array}$ & {$[0.46]$} \\
\hline$A_{\text {produced }}\left(\times 10^{10}\right)$ & $\begin{array}{l}\text { North American } \\
\text { New Zealand } \\
\text { Mean }\end{array}$ & {$[0.88]$} & $\begin{array}{l}3.47(1.02) \\
4.90(0.82) \\
4.34\end{array}$ & $\begin{array}{l}3.59(0.97) \\
3.53(0.79) \\
3.56\end{array}$ & $\begin{array}{l}3.54 \\
4.19 \\
3.93\end{array}$ & {$[0.90]$} \\
\hline
\end{tabular}

${ }^{1}$ Differences significant at the $0.05(*), 0.01(* *)$ and $0.001(* * *)$ levels.

value of $4.56 \mathrm{~d}^{-1}$ for heifers fed grass, and a value of $5.55 \mathrm{~d}^{-1}$ for heifers fed TMR, indicating that the TMR diet enhanced the probability of a quiescent alveolus becoming reactivated. The average value for $k_{4}$ over all heifers was $5.08 \mathrm{~d}^{-1}$.

There was a strong diet effect $(P<0.001)$ in the value of the scenescence parameter, $k_{5}$, but no genotype effect. For heifers fed grass, $k_{5}$ was $3.22 \times 10^{-1} \mathrm{~d}^{-1}$, and 1.33 $\times 10^{-1} \mathrm{~d}^{-1}$ for heifers fed TMR, indicating a greater senescence rate for quiescent alveoli in heifers fed grass. The average of $k_{5}$ over all heifers was $2.23 \times 10^{-1} \mathrm{~d}^{-1}$.

There were no genotype or dietary effects on $L$, which had a value of 0.567 . The absence of dietary effects is to be expected, since $L$ governs the degree to which a heifer buffers its milk production when under nutritional stress. According to the model, with $L=0.567$, a heifer at $75 \%$ energy status $(E=0.75)$ would be at $85 \%$ production when compared to its production at maximal feeding; at $50 \%$ energy status, it would be at $68 \%$ production. Figure 2 shows example fits from each of the four treatment groups, together with the energy status (supplied as an input during fitting), and the model estimate of active alveoli population with time. Because milk yield is a function of both alveolar population, and nutrition, the shape of the alveolar curve is modulated by the energy status curve to give the fitted lactation curve. Thus, peak milk yield does not always coincide with peak alveolar population.

Figures 3 and 4 show the evolution, over time, of the populations of active and quiescent alveoli for the different genotypes and diets (using the corresponding parameter values in Table 1).

Rates of decline of active alveoli were less for heifers fed TMR than for heifers fed grass, indicating better persistency with TMR, and over the course of a lactation, a larger population of active alveoli. This effect can be linked to differences between diets in the senescene parameter, $k_{5}$. In terms of persistency of alveoli, the New Zealand genotype performed better than the North American genotype on grass, but underperformed the North American genotype on TMR, possibly reflecting differences in breeding selection criteria in the two countries. Such a difference may be linked to the genotype $\times$ diet effect found in the quiesence parameter, $k_{3}$. Quiescent alveoli followed opposite trends to active alveoli, with a grass diet resulting in more quiescent alveoli at the expense of active alveoli, for the first part of the lactation. By around midway through the lactation, this difference disappeared due to the much greater losses in total alveoli suffered by the heifers on a grass diet (due to a greater senescence rate, reflected in a higher value of $k_{5}$ ). After an initial equilibriating 

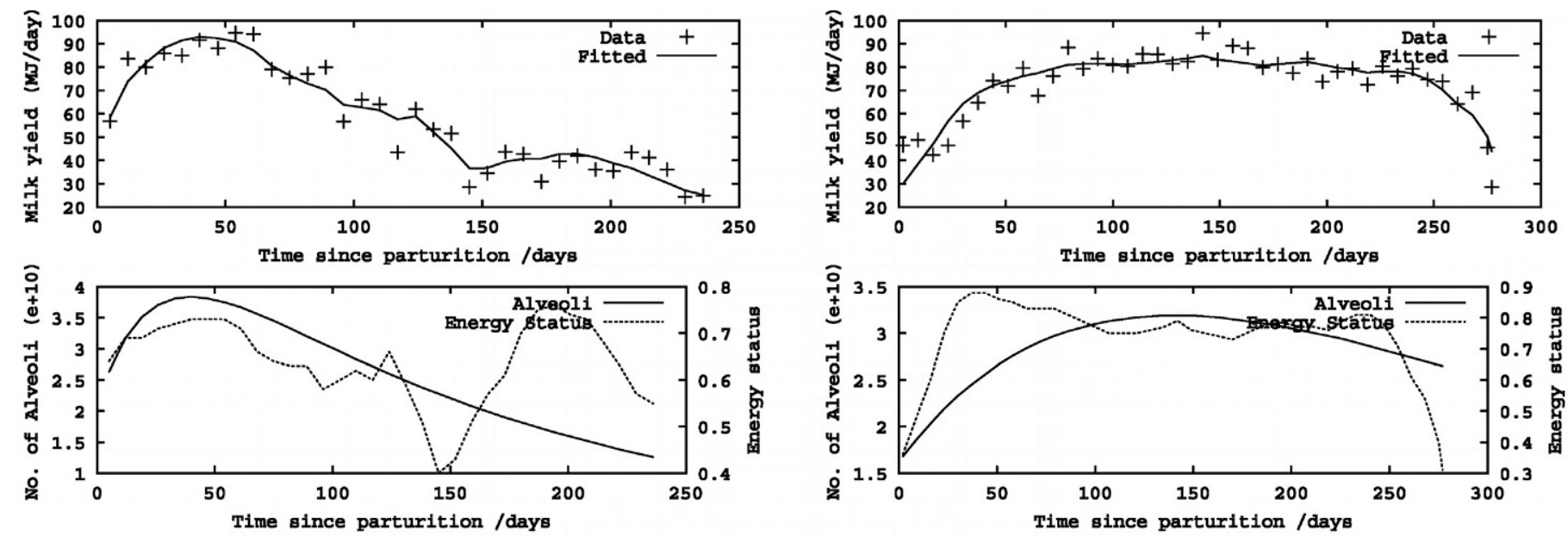

(a) North American Grass

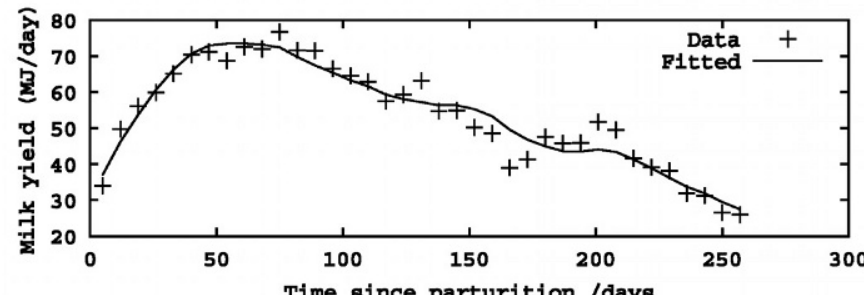

(b) North American TMR

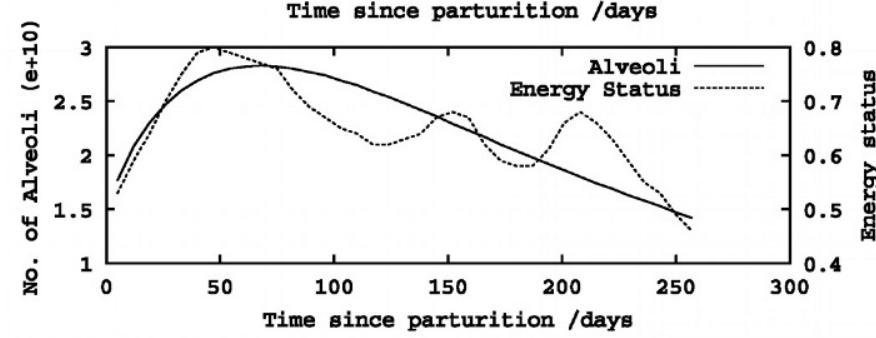

(c) New Zealand Grass
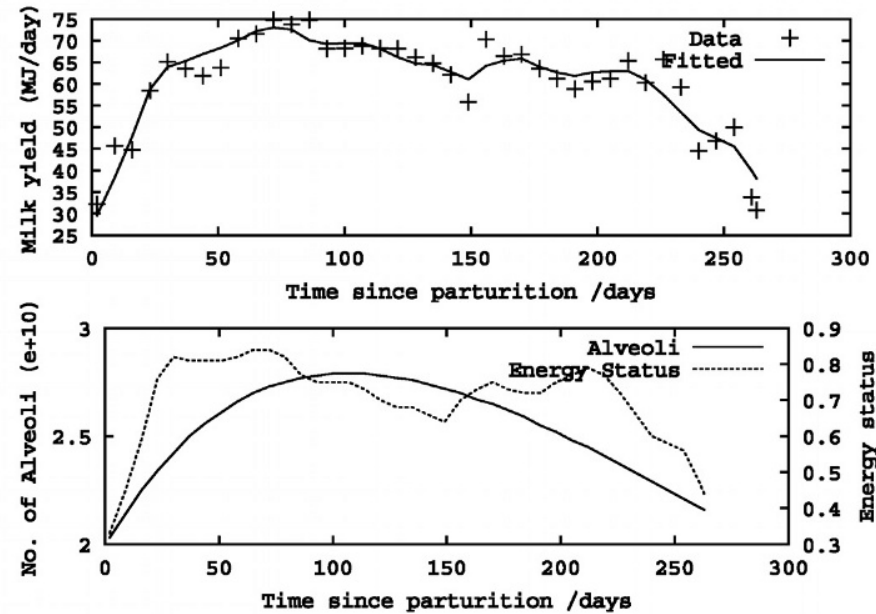

(d) New Zealand TMR

Figure 2. Example fits for each of the New Zealand Grass and TMR groups, showing fit of model to milk yield data, model estimate of number of active alveoli, and energy status (used as an input).

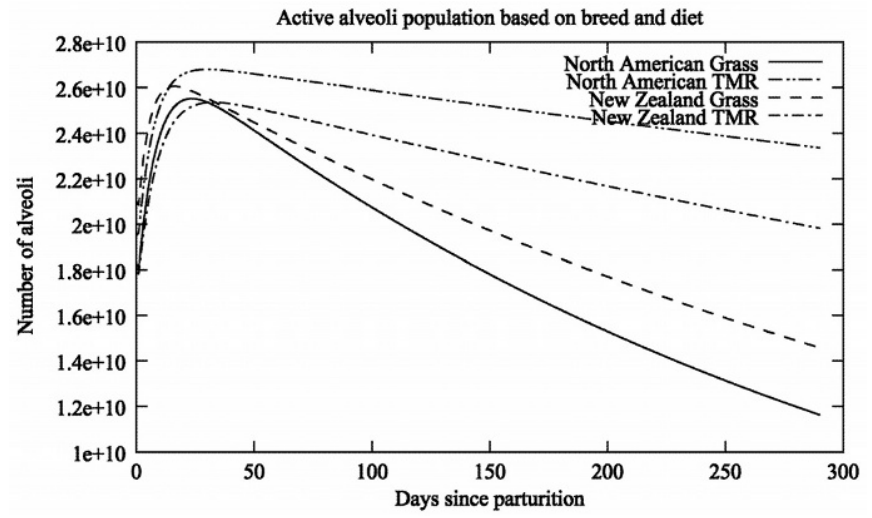

Figure 3. Active alveoli populations with time for the different treatment groups.

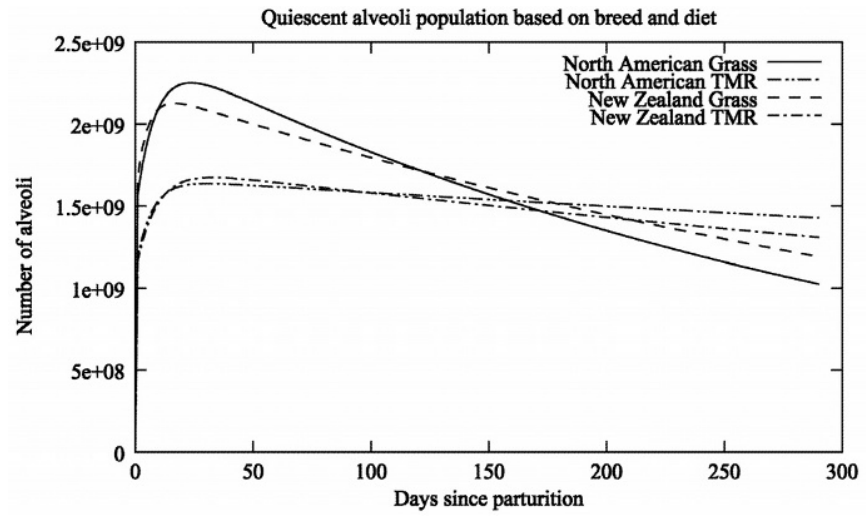

Figure 4. Quiescent alveoli populations with time for the different treatment groups. 
period of a few days, the ratio of active to quiescent alveoli was constant over the lactation. The higher this ratio, the larger the proportion of total alveoli being used for milk secretion. For North American heifers, this ratio was 16.4 on TMR and 11.3 on grass, whereas for New Zealand heifers, it was 15.1 on TMR and 12.2 on grass. Thus, in terms of utilizing alveoli for secretion, North American heifers were better than New Zealand heifers on TMR, but worse on grass. This effect is again likely to be linked to the genotype-diet effect found in $k_{3}$.

\section{DISCUSSION}

The formulation of a model of the physiology of milk production in cows based on the observed biological interactions provides the basis for testing hypotheses about the effect of various management strategies at the physiological level. Previously, management strategies were evaluated as they affected the main observable variable, in this case milk production. This mechanistic model enables the examination of how the components that make up milk production vary in relation to effects such as nutritional level and genotype. The identification of these physiological effects and how they change provides important information to scientists seeking to understand variation in milk production.

The most apparent effect of diet was on rate of senescence of quiescent alveoli, which was significantly higher on the poorer diet, for both genotypes. Thus, from a management point of view, diet may be a key factor in improving persistency of lactation for HolsteinFriesians being milked twice daily, as was the case for all the cows in this study. Milking frequency affects persistency (Davis et al., 1999). How diet interacts with milking frequency will be the basis of further study. The model provides improvements over previous models in the literature in two important ways: First, it more closely reflects current biological knowledge by distinguishing between mammary secretory tissue in active and quiescent states, which facilitates interpretation of data within a framework of current understanding.

Second, it explicitly models the acute effects of nutrition on milk secretion, allowing the chronic effects of nutrition on mammary growth and regression to be quantified. The application of the model to identifying the differences between New Zealand and North American heifers provides insight into the mechanisms underlying the differences in milk production between these two genotypes. In particular, the model suggests that the main difference lies in the reactivation of the quiescent alveoli, but importantly, that this difference is diet dependent. Thus, it appears that the different selection pressures that have been applied to each of these genotypes have acted on the quiescent to active pathway. The North American heifers have been selected for production under concentrate feeding conditions and have shown greater responsiveness to the different diets. The New Zealand heifers have been selected to produce consistently subject to the greater variation of a pasture-based system, and this has resulted in less responsiveness to diet of the pathways involving reactivation of quiescent alveoli to their active state. The difference between the two genotypes is expressed in the $k_{3}$ parameter, and therefore it is possible that more efficient selection for milk production in North American cows could be achieved by selecting directly for an increase in the parameter $k_{3}$ in equation 23 when the cows are fed a grass diet. Whether New Zealand cows express sufficient variation in this parameter to make selection worthwhile cannot be determined from this experiment. There was no significant difference between the four groups in total production of alveoli during pregnancy and lactation.

Capuco et al. (2001) made direct estimates of cell proliferation and apoptosis, from d 14 of lactation and concluded that cell proliferation was not a significant contributor to the increase in milk production from parturition until the peak of lactation. They acknowledged, however, that some mammary growth may have occurred before their measurement period. Indeed, for the average value of $k_{2}$ found in the present study, cell proliferation would decline to $12 \%$ of its parturition value by d 14 of lactation, and to $1 \%$ by d 30 . Eighty eight percent of cell proliferation during lactation would occur in the first $2 \mathrm{wk}$. Based on the average values for $A_{0}$ and $k_{1}$, the period from d 14 onwards would contribute only $4 \%$ of the total cell proliferation occurring during development and lactation. Thus the authors draw the different conclusion that cell proliferation can play a significant part in increasing production before the peak.

Capuco et al. (2001) suggested that by the end of lactation more than half the cells in the udder would have been renewed. They obtained values of $0.56 \%$ per day for the rate of apoptosis and $0.3 \%$ per day for the rate of proliferation, during the entire period of post peak lactation. These estimates were based on indices of proliferation and apoptosis, and are the best estimates currently available for the bovine. A constant level of cell proliferation postpeak is not consistent with the model's expression for the rate of proliferation, $r_{p a}$, which dies away exponentially to zero (equation 6 ). The model could be refined to include an underlying rate of cell turnover by ensuring that $r_{p a}$ declines to a nonzero level. This would have the net result of increasing the estimate of $r_{q s}$, the rate of apoptosis, in order to maintain the same alveolar population. However, such turn- 
over could be associated with individual cell renewal within active alveoli rather than generation of new secretory alveoli, so inclusion of such a refinement was deferred.

The assumption made, in the model development, that there were no quiescent alveoli at parturition, served to reduce, by one, the number of parameters in the model that would need to be fitted. Whereas this assumption seems plausible from a biological point of view, even if it were incorrect, it would have little impact on the results: the proportion of quiescent alveoli was never more than 6 to $8 \%$ of the total alveoli, and the model reaches an equilibrium between the ratio of quiescent to active alveoli soon after parturition, and the time taken to do this is small compared with the length of a lactation. This paper illustrates the potential of a nonlinear mechanistic model, incorporating knowledge about the relationships between the physiological components, to contribute to understanding of milk production. This paper has demonstrated the ability of these models to derive information about the effect of management and breeding strategies on milk production. In particular, the model is able to identify potential new criteria for selection of superior cattle.

\section{REFERENCES}

Brent, R., 1973. Algorithms for Minimization Without Derivatives. Prentice Hall, Englewood Cliffs, NJ.

Capuco, A. V., D. L. Wood, R. Baldwin, K. Mcleod, and M. J. Paape. 2001. Mammary cell number, proliferation and apoptosis during a bovine lactation: Relation to milk production and effect of bST. J. Dairy Sci. 84:2177-2187.

Dado, R. G., D. R. Mertens, and G. E. Shook. 1993. Nutrition, feeding, and calves. Metabolisable energy and absorbed protein requirements for milk component production. J. Dairy Sci. 76:1575-1588.

Davis, S. R., V. C. Farr, M. J. Auldist, and E. S. Kolver. 2000. Effects of diet on udder function and regression in Holstein-Fresian cattle. Proc. N.Z. Soc. Anim. Prod. 60:275-276.

Davis, S. R., V. C. Farr, P. J. A. Copeman, V. R. Carruthers, C. H. Knight, and K. Stelwagen. 1998. Partitioning of milk accumulation between cisternal and alveolar compartments of the bovine udder: Relationship to production loss during once daily milking. J. Dairy Res. 65:1-8.

Davis, S. R., V. C. Farr, and K. Stelwagen. 1999. Regulation of yield loss and milk composition during once-daily milking: A review. Livest. Prod. Sci. 59:77-94.

Dijkstra, J., J. France, M. S. Dhanoa, J. Maas, M. D. Hanigan, A. J. Rook, and D. E. Beever. 1997. A model to describe growth patterns of the mammary gland during pregnancy and lactation. J. Dairy Sci. 80:2340-2354.

Emmans, G. C., and C. Fisher. 1986. Problems in nutritional theory. Pages 9-39 in Nutrient Requirements of Poultry and Nutritional Research. C. Fisher and K. N. Boorman, eds. Butterworths, London.
Farr, V. C., K. Stelwagen, L. R. Cate, A. J. Molenaar, T. B. McFadden, and S. R. Davis. 1996. An improved method for the routine biopsy of bovine mammary tissue. J. Dairy Sci. 79:543-549.

Friggens, N. C., G. C. Emmans, and R. F. Veerkamp. 1999. On the use of simple ratios between lactation curve coeffcients to describe parity effects on milk production. Livest. Prod. Sci. 62:1-13.

Hohenboken, W. D., A. Dudley, and D. E. Moody. 1992. A comparison among equations to characterize lactation curves in beef cows. Anim. Prod. 55:23-28.

Holmes, C. W., and G. F. Wilson. 1984. Milk Production from Pasture. Butterworths, Wellington, NZ.

Jenkins, T. G., and C. L. Ferrell. 1984. A note on lactation curves of crossbred cows. Anim. Prod. 39:479-482.

Knight, C. H., J. France, and D. E. Beever. 1994. Nutrient metabolism and utilization in the mammary gland. Livest. Prod. Sci. 39:129-137.

Knight, C. H., and C. J. Wilde. 1993. Mammary cell changes during pregnancy and lactation. Livest. Prod. Sci. 35:3-19.

Kolver, E. S., A. R. Napper, P. J. A. Copeman, and L. D. Muller. 2000. A comparison of New Zealand and overseas Holstein Friesian heifers. Proc. N.Z. Soc. Anim. Prod. 60:265-269.

Molenaar, A. J., S. R. Davis, and R. J. Wilkins. 1992. Expression of $\alpha$-lactalbumin, $\alpha$-S1-casein, and lactoferrin genes is heterogeneous in sheep and cattle mammary tissue. J. Histochem. Cytochem. 40:611-618.

Morant, S. V., and A. Gnanasakthy. 1989. A new approach to the mathematical formulation of lactation curves. Anim. Prod. 49:151-162.

Neal, H. D. S. C., and J. H. M. Thornley. 1983. The lactation curve in cattle: A mathematical model of the mammary gland. J. Agric. Sci. Camb. 101:389-400.

Nestorov, I., M. Rowland, S. T. Hadjitodorov, and I. Petrov. 1999. Empirical versus mechanistic modelling: Comparison of an artificial neural network to a mechanistically based model for quantitative structure pharmacokinetic relationships of a homologous series of barbiturates. AAPS Pharmsci 1 (4), Article 17, available on-line at http://www.pharmsci.org.

Olori, V. E., S. Brotherstone, W. G. Hill, and B. J. McGuirk. 1999. Fit of standard models of the lactation curve to weekly records of milk production of cows in a single herd. Livest. Prod. Sci. 58:55-63.

Papajcsik, I. A., and J. Bodero. 1988. Modelling lactation curves of Friesian cows in a subtropical climate. Anim. Prod. 47:201-207.

Sakul, H., and W. J. Boylan. 1992. Lactation curves for several US sheep breeds. Anim. Prod. 54:229-233.

Shorten, P. R., I. Vetharaniam, T. K. Soboleva, G. C. Wake, and S. R. Davis. 2002. Influence of milking frequency on mammary gland dynamics. J. Theor. Biol. 218, 521-530.

Somerville, S. H., B. G. Lowman, and R. A. Edwards. 1983. A study of the relationship between plane of nutrition during lactation and certain production characteristics in autumn-calving suckler cows. Anim. Prod. 37:353-363.

Vetharaniam, I., D. G. McCall, P. F. Fennessy, and D. J. Garrick. 2001. A model of mammalian energetics and growth: Model development. Agric. Sys. 68:55-68.

Weber, A. F., R. L. Kitchell, and J. H. Sauter. 1955. Mammary gland studies. 1 . The identification and characterisation of the smallest lobule unit in the udder of the dairy cow. Am. J. Vet. Res. 16:255-263.

Williams, J. C. 1993. An empirical model for the lactation curve of white British dairy goats. Anim. Prod. 57:91-97.

Wood, P. D. P. 1967. Algebraic model of the lactation curve in cattle. Nature 216, 164-165.

Wood, P. D. P. 1977. The biometry of lactation. J. Agric. Sci. Camb. 88, 333-339. 